\title{
O PAPEL FISCALIZADOR DA SEMA/MT NA REGIÃO DO BAIXO ARAGUAIA
}

\author{
Bruno Teixeira Guimarães ${ }^{1}$ \\ Ronny Cesar Camilo Mota ${ }^{2}$
}

RESUMO: Este artigo científico trata sobre "O Papel Fiscalizador da SEMA/MT na Região do Baixo Araguaia", e tem como problema: "existe eficácia e eficiência no papel da SEMA/MT em sua função fiscalizadora na região do Baixo Araguaia?". Assim, seu objetivo é analisar se há eficácia e eficiência da SEMA/MT na Região do Baixo Araguaia. Para chegar a conclusão final deste trabalho foi utilizada a pesquisa de natureza básica, e, quanto a sua forma, esta é quanti-qualitativa. É, também, uma pesquisa descritiva, além de ser explicativa. Já no que se diz respeito aos procedimentos técnicos, se utiliza da pesquisa bibliográfica, realizando, também, a análise documental, a pesquisa de campo, e, quanto ao método de abordagem, este é dedutivo. O procedimento é estatístico. Na fundamentação da pesquisa, utiliza-se Betiol (2010), Leite, Moreira e Achkar (2006), Robalo (1995), a Constituição Federal (1988), a Lei Complementar de Mato Grosso $n^{\circ}$ 214/2005 que institui a SEMA, e a Lei 6.938/1981 da Política Nacional de Meio Ambiente. No decorrer da pesquisa, foi possível observar que as leis nacionais a respeito da proteção do meio ambiente são atualizadas, atendendo as necessidades do povo e seguindo o pensamento ambiental internacional, porém, a falha encontrada está no modo de execução destas leis, não pelo órgão, mas sim pelo Estado, que não disponibiliza verba suficiente para a manutenção dos serviços. Mas, a Unidade Desconcentrada de Barra do Garças, neste contexto de negligência do Estado, consegue atingir a média estadual, cumprindo seu dever com eficácia e eficiência.

PALAVRAS CHAVE: SEMA. Eficácia. Eficiência. Meio ambiente.

\footnotetext{
${ }^{1}$ Acadêmico do $8^{\circ}$ Semestre do Curso de Direito da Faculdade de Ciências Jurídicas e Sociais Aplicadas do Araguaia - FACISA.

${ }^{2}$ Mestre em Direito, Relações Internacionais e Desenvolvimento. Professor do Curso de Direito da Faculdade de Ciências Jurídicas e Sociais Aplicadas do Araguaia - FACISA.
} 


\begin{abstract}
This scientific article deals with "The Supervisory Role of SEMA / MT in the Lower Araguaia Region", and has the following problem: "Is there efficiency and effectiveness in the role of SEMA / MT in its oversight function in the Lower Araguaia region?" . Thus, its objective is to analyze whether there is efficiency and effectiveness of SEMA / MT in the Lower Araguaia Region. To reach a final conclusion of this work, a research of a basic nature was used, and its form, it is quantitative and qualitative. Also, a descriptive research, besides being explanatory. It is no longer the case of respecting technical procedures, using bibliographic research, conducting also a documentary analysis, a field research and the method of approach is deductive. The procedure is statistical. The research is based on Betiol (2010), Leite, Moreira and Achkar (2006), Robalo (1995), Federal Constitution (1988), Complementary Law of Mato Grosso No. 214/2005 establishing the SEMA, and Law 6.938 / 1981 of the National Environmental Policy. In the course of the research, it was possible to observe how national laws respect the protection of the environment are updated, meeting the demands of the people and following environmental thinking. but by the state, which does not provide enough mon the services. But a Disconnected Barra de Garças Unit, in this context of manages to achieve the state average, fulfilling its duty efficiently and effectivel
\end{abstract}

KEY WORDS: SEMA. Effectiveness. Efficiency. Environment. 


\section{INTRODUÇÃO}

Com a Constituição Federal (CF) de 1988, mais especificamente em seu artigo 225, pela primeira vez na história brasileira, o meio ambiente é tratado com a devida atenção.

E, esta atenção, é de extrema importância, pois a legislação brasileira passa a seguir uma movimentação crescente em todo o mundo, tendo como ponto de partida, a Conferência de Estocolmo em 1972, que deu início a uma preocupação, cada vez maior, com o meio ambiente, tendo em vista que sem ele o homem não é capaz de manter uma vida saudável.

E, com base nessas considerações constitucionais, nascem os objetivos da Secretaria de Estado de Meio Ambiente (SEMA), órgão de nível estadual, criado no Estado de Mato Grosso pela Lei Complementar $\mathrm{n}^{\circ} 214$ de junho de 2005, com o objetivo de assegurar a preservação do meio ambiente aplicando políticas públicas para a fiscalização, educação ambiental e ações específicas para determinados casos, como a prevenção de queimadas e desmatamentos, sempre com o intuito de observar a melhora na qualidade de vida do ser humano e a verificar os parâmetros do desenvolvimento sustentável.

Neste contexto, este artigo científico tem como tema "O Papel Fiscalizador da SEMA/MT na Região do Baixo Araguaia", buscando analisar o seguinte problema: "existe eficácia e eficiência no papel da SEMA/MT em sua função fiscalizadora na região do Baixo Araguaia?"

E, tendo em vista o tema e problema tratados, como objetivo geral desta pesquisa busca-se analisar a eficácia e a eficiência da SEMA/MT na Região do Baixo Araguaia, que compreende 16 municípios, sendo eles: Ribeirãozinho, Torixoréu, Pontal do Araguaia, Barra do Garças, Araguaiana General Carneiro, Novo São Joaquim, Campinápolis, Nova Xavantina, Água Boa, Nova Nazaré, Cocalinho, Canarana, Gaúcha do Norte, Ribeirão Cascalheira e Querência, tendo como órgão atuante tão somente a Diretoria de Unidade Desconcentrada de 


\section{Barra do Garças (DUDBARRA).}

Sobre os objetivos específicos, esta pesquisa busca conceituar e definir a SEMA/MT, descrever quais são as políticas de fiscalização adotadas, observar os dados destas políticas e verificar a eficácia e eficiência da SEMA/MT.

Deste modo, esta pesquisa é básica quanto a sua natureza, tendo em vista que busca acrescentar conhecimentos científicos apresentando os dados coletados e verificando, com base nestes dados, se de fato o que o legislador busca ao traçar objetivos é cumprido pelo órgão competente.

Já quanto a forma, como se aborda a pesquisa, esta é quanti-qualitativa, pois, traz dados traduzidos em números, e, também, é emitido um juízo de valor, analisando, objetivamente, os dados apresentados para que se atinja os objetivos da pesquisa. É, também, uma pesquisa descritiva, pois esclarece os dados de determinadas políticas públicas fiscalizadoras com uma observação sistemática, bem como, é uma pesquisa explicativa, pois analisa as políticas de fiscalização, apresentando o porquê de serem ou não mais eficazes e eficientes.

No que se diz respeito aos procedimentos técnicos, se utiliza da pesquisa bibliográfica, pois os dados foram obtidos em materiais já publicados, como: livros, artigos científicos, além de materiais encontrados na internet. É, também, realizado o procedimento de análise documental, pois é verificado junto a SEMA/MT, os programas de fiscalização empregados na região do Baixo Araguaia e os dados dos mesmos, além da pesquisa de campo, já que a abordagem é feita no ambiente da Secretaria, com a anuência expressa do Professor, ex Diretor do órgão, Cleber Fabiano Ferreira, que durante a sua gestão deu ampla abertura para a execução da pesquisa.

O método de abordagem utilizado é o dedutivo, ou seja, se parte de premissas gerais até chegar a SEMA/MT, Diretoria de Unidade Desconcentrada de Barra do Garças, que atua na região do Baixo Araguaia, analisando a mesma, enquanto o método de procedimento consubstancia-se no estatístico, pois o resultado da pesquisa depende da análise dos números obtidos das atividades e diligências fiscalizadoras empregadas pelo órgão na região atuante.

Na fundamentação da pesquisa, utiliza-se Betiol (2010), Leite, Moreira e Achkar (2006), Robalo (1995), a Constituição Federal (1988), a Lei Complementar de Mato Grosso $\mathrm{n}^{\mathrm{o}}$ 214/2005 que institui a SEMA, e a Lei 6.938/1981 da Política Nacional de Meio Ambiente.

Ainda, este artigo aborda o conceito de meio ambiente definindo-o em todas as suas formas estabelecidas pela doutrina; desenvolvimento econômico e o meio ambiente, 
fazendo uma breve retomada história de como a humanidade lida com este assunto; definição da SEMA, de acordo com a lei complementar que a cria; distinção entre eficácia e eficiência conceituando ambos para que não haja confusão; o detalhamento da estrutura material disponibilizada pelo Estado de Mato Grosso à SEMA, Unidade de Barra do Garças para a realização de suas diligências; a descrição das atividades realizadas pela SEMA no lapso temporal de 4 anos, sendo eles, 2011, 2012, 2013 e 2014; a observação dos dados destas atividades. E, por fim; verifica se existe eficácia e eficiência na atuação da SEMA/MT desta região.

Isto posto, esta pesquisa traduz as informações colhidas junto a SEMA/MT, núcleo de Barra do Garças, em números, analisando junto a legislação competente se o objetivo (eficiência e eficácia) das fiscalizações é positivo, apresentando, ao final, uma possível forma de melhora da situação observada.

\section{CONCEITUAÇÃO DE MEIO AMBIENTE}

O conceito de meio ambiente é difícil de ser obtido, tendo em vista seu vasto campo. A lei 6.938/81, que trata da Política Nacional do Meio Ambiente, ao tentar descrevêlo pecou, sofrendo duras críticas pela doutrina, por não abranger todas as suas formas, ficando adstrito ao meio ambiente natural. Ela entende que o meio ambiente é, "o conjunto de condições, leis, influências e interações de ordem física, química e biológica, que permite, abriga e rege a vida humana" (BRASIL, 1981, disponível em: www.planalto.gov.br), conceito muito amplo.

Deste modo, restou à doutrina a função de conceituar o meio ambiente nas demais formas - urbano, cultural e do trabalho, asseverando que, o meio ambiente urbano/artificial, é aquele construído por obra humana, como as casas, prédios, ruas, estradas e cidades.

Já o meio ambiente cultural, apesar de também ser criado por obra humana, se diferencia do urbano por ter um valor artístico superior que foi a ele ligado pelos mais diversos fatores. Como exemplo pode-se notar a Torre Eiffel, em Paris, na França, a Muralha da China, no nordeste da China, e o Cristo Redentor, no Rio de Janeiro, Brasil. E, o meio ambiente do trabalho, como o próprio nome já diz, é aquele em que são desenvolvidas atividades trabalhistas humanas como as indústrias, escritórios e lojas.

Por fim, a doutrina define o meio ambiente como: 
relação de interdependência entre seus componentes. Trata-se de uma entidade dinâmica, cujo complexo de interações proporciona e mantém a vida, em todas as suas formas, e que os danos causados a um dos elementos que a integra podem repercutir nos demais, prejudicando a cadeia de interação entre eles e ameaçando a sobrevivência. (LEITE, MOREIRA E ACHKAR, 2006, p.08)

Em geral, os conceitos globais sobre o tema variam, mas o que a doutrina traz na sua essência tem sempre a mesma definição, e o que temos que ter em mente é que o meio ambiente não é tão somente florestas, a água e o ar, mas sim todo tipo de ordem física contida no mundo.

Mas, o meio ambiente é protegido de tal forma porque, para se ter uma vida saudável, o ser humano, que é o ponto central da preocupação jurídica mundial, necessita de um ambiente salubre para reger bem a sua vida. E não precisa de um ambiente salubre por determinado lapso temporal, mas sim que dure para sempre.

Este é o ponto central do desenvolvimento sustentável, que se propõe a fundir o meio ambiente com o desenvolvimento econômico, tarefa de difícil realização, mas necessária à vida humana.

\section{DESENVOLVIMENTO ECONÔMICO E O MEIO AMBIENTE}

A Constituição Federal de 1988, no que tange ao desenvolvimento econômico do país em relação ao meio ambiente, não adota uma posição, já que não define se a atenção máxima será dada ao desenvolvimento ou ao meio ambiente. E, isso pode ser visto de forma intrínseca no texto constitucional, pois, este trata como objetivo nacional o desenvolvimento, ao mesmo tempo em que traz o meio ambiente como bem indispensável à sadia qualidade de vida.

E, o legislador constituinte vincula o meio ambiente com o direito à vida, pois, conforme destaca Chimenti:

há nítida vinculação da proteção do meio ambiente com o direito á vida $(\mathrm{CF}$, art. $5^{\circ}$ ), possuindo a natureza de direito fundamental. Detém, ainda, caráter intergeracional (a proteção se dá para a garantia da qualidade de vida das presentes e futuras gerações). A proteção ambiental também constitui limite para a atividade econômica (CF, art.170). (CHIMENTI, 2010, p.627).

Deste modo, cumpre ressaltar, que tanto o desenvolvimento econômico quanto o meio ambiente, sem a devida atenção se tornam efetivos rivais, pois se esta atenção é dada a somente um, o outro sempre restará prejudicado, sem poder se desenvolver da forma correta. 
Neste ponto, se inicia uma luta constante a fim de conciliar estes dois campos tão importantes na vida do ser humano.

E, não foi só no Brasil, mas em todo o mundo, a questão meio ambiente/economia é alvo de um impasse e é tratada com maior atenção, já que o homem, com a explosão mundial iniciada com a revolução industrial e os seguidos avanços tecnológicos, percebeu que, sem a devida atenção, o meio ambiente é incapaz de se renovar, parando não só o desenvolvimento econômico de uma nação como, também, a vida humana, que não subsiste muitos anos neste ritmo.

E, isto se dá, conforme destaca Betiol, porque:

Diante da percepção dessas incapacidades, surgiram, especialmente no final da década de 1960 e início da década de 1970, análises do impacto de restrições ambientais sobre o crescimento econômico e da escala da economia sobre o meio ambiente. (BETIOL, 2010, p.33)

Mas, especificamente em 1972, na Conferência das Nações Unidas sobre o Meio Ambiente Humano, evento que é reconhecido como o ponto de partida do pensamento do meio ambiente em si, pela primeira vez, a humanidade, representada pelos poderes governamentais de cada país, se reuniram para tratar deste assunto.

O tema não foi bem recebido pelos países subdesenvolvidos e de atividade principal industrial, tendo em vista que seu desenvolvimento socioeconômico, de certa forma, restaria prejudicado com essa crescente mundial tentando diminuir a emissão de poluentes, o que, de fato é um grande "atraso" ao desenvolvimento de uma nação, mas é uma questão que merece o devido respeito, pois, somente assim, poderá ser atingido o princípio de número 3 da Conferência de Estocolmo, que trata: "Princípio 3. Deve-se manter, e sempre que possível, restaurar ou melhorar a capacidade da terra em produzir recursos vitais renováveis."(ESTOCOLMO, 1972, disponível em: www.apambiente.pt)

E, após este ponto inicial, dado com a Conferência de 1972, diversos estudos e novas reuniões vem sendo feitas no decorrer dos anos, tudo para que o pensamento ecológico se dissemine.

No Brasil, de forma a seguir o pensamento mundial, foi instituído capítulo próprio para tratamento do tema na Constituição Federal vigente (capítulo IV), inclusive sendo alçado ao patamar de direito fundamental quando o condiciona à sadia qualidade de vida, que é, intrinsecamente, ligada ao Princípio da Dignidade da Pessoa Humana.

Conforme ensina Maria Helena Diniz, o meio ambiente é "Habitat, ou seja, lugar onde se vive sob influência das leis físico-naturais, cuja fauna e flora devem ser preservadas, 
devendo-se para tanto combater a poluição e as prátivas que possam ser lesivas a elas, sob pena de responsabilidade civil."(DINIZ, 2010, p.394).

Assim, a Constituição determina que, para a efetivação deste direito à toda coletividade, de modo geral, a fiscalização deve ser feita em todo o país, e, deste modo, preceitua a instituição de órgão específico para o tratamento do tema, com poderes, inclusive, para penalizar e imputar responsabilidade civil ao agressor do meio ambiente, sendo esta, em nível estadual, a SEMA.

\section{RESPONSABILIDADE AMBIENTAL}

Ponto importante a se tratar na esfera ambiental é a responsabilidade do agressor do meio ambiente e o modo como esta se dará.

No ordenamento jurídico brasileiro, hoje, a responsabilidade ambiental decorre diretamente do artigo $225, \S 3^{\circ}$ da Constituição Federal, que trata:

Art. 225

[...]

$\$ 3^{\circ}$. as condutas e atividades consideradas lesivas ao meio ambiente sujeitarão os infratores, pessoas físicas ou jurídicas, a sanções penais e administrativas, independentemente da obrigação de reparar os danos. (BRASIL, 1988, disponível em: www.planalto.gov.br).

Esta responsabilização pode ser dividida em 3 vertentes, a civil, administrativa e penal.

No caso da civil, esta se trata de responsabilidade civil objetiva, ou seja, independente de culpa do agressor, este poderá ser responsabilizado, pois sua atividade é de risco para os direitos de outrem. Além disso, o poluidor poderá ser tanto pessoa jurídica quanto física.

Neste caso, o infrator é obrigado a reparar o dano de acordo com sua extenção.

Em se tratando de responsabilidade administrativa, a Lei $n^{\circ} 9.605 / 98$, chamada de Lei dos Crimes Ambientais, adverte que:

Art. 70. Considera-se infração administrativa ambiental toda ação ou omissão que viole as regras jurídicas de uso, gozo, promoção, proteção e recuperação do meio ambiente. (BRASIL, 1998, disponível em: www.planalto.gov.br).

Caso ocorra infração administrativa, as penas podem variar de uma advertência até uma suspensão total ou parcial das atividades.

Já no que se tange a responsabilidade penal, a mesma Lei dos Crimes Ambientais, 
por exemplo, tipifica delitos e pode punir tanto pessoas físicas como pessoas jurídicas em caso de enquadramento em um de seus tipos penais.

As penas, em caso de responsabilidade penal podem ser privativas de liberdade, restritivas de direitos e multa.

E, o órgão Estadual incumbido na fiscalização de tal responsabilidade ambiental é a SEMA, a quem se passa a estudar.

\section{SECRETARIA DE ESTADO DE MEIO AMBIENTE (SEMA/MT)}

A SEMA, no Estado de Mato Grosso foi instituída pela Lei Complementar $\mathrm{n}^{\circ}$ 214/2005, em que consta seus objetivos, finalidades, estrutura organizacional, competência, órgãos, dentre outras disposições pertinentes a regulamentação desta secretaria.

E, o artigo $3^{\circ}$ de tal lei trata sobre a finalidade do referido órgão da seguinte forma:

Art. $3^{\circ}$ constituem finalidades da SEMA, garantir o controle, a preservação, a conservação e a recuperação ambiental, a preservação permanente contra desastres e acidentes naturais ou provocados pelo homem, assistência e recuperação dos eventos danosos, bem como contribuir para o desenvolvimento sustentável em benefício da qualidade de vida do povo mato-grossense (BRASIL, 2005, disponível em: www.sefaz.mt.gov.br)

Ainda, à SEMA/MT compete, dentre outras atribuições, se conveniar com entidades que tenham interesse ambiental; propor normas que julgar necessárias; exercer o poder de polícia ambiental no Estado; monitorar os recursos ambientais do estado; bem como a fiscalização e, inclusive, a aplicação de penalidades quando da observação de infração ambiental, de acordo com a responsabilidade ambiental cabível, seja administrativa, penal ou civil.

Tal lei, além de ter instituído a SEMA/MT, extinguiu a FEMA (Fundação Estadual do Meio Ambiente), o que proporcionou uma atuação mais ampla no que se diz respeito aos setores de atuação, podendo, assim, por exemplo, criar superintendências para a observação específica de resíduos sólidos, avaliação de impacto ambiental, acidentes ambientais, gestão do fogo, ecossistemas, parques urbanos e outros casos previstos na própria lei.

No caso do núcleo de Barra do Garças-MT, este se trata de uma Diretoria de Unidade Desconcentrada e uma Gerência Regional Parque Serra Azul da SEMA/MT, que estão previstas na Lei Complementar 214/2005. 
Observa-se que, para se chegar aos objetivos do órgão com eficácia e eficiência, a fiscalização e a imputação de penalidades é um dos principais mecanismos adotados, já que gera uma forma de coerção diante da sociedade em geral.

Interessante notar a diferença existente entre eficácia e eficiência e analisar, enfim, se o órgão cumpre com tais conceitos.

\section{EFICÁCIA E EFICIÊNCIA}

Tendo em vista que o objetivo deste trabalho é verificar se a SEMA/MT cumpre seu papel fiscalizador com eficácia e eficiência, é necessária a discussão sobre a diferença existente entre as duas palavras, para que não haja confusões durante a apresentação dos resultados da pesquisa.

É certo que entre os dois conceitos corre muita incerteza, sendo que muitos acreditam se tratar de sinônimos, o que de verdade não é.

Assim, "eficiência tem genericamente que ver com o modo como se obtém determinados resultados. Um método é mais eficiente que outro se para atingir o mesmo resultado exige menor dispêndio de recursos." (ROBALO, 1995, p.107)

Já a eficácia "refere-se sobretudo ao fato de se atingir ou não o objetivo e se esse objetivo é realmente o objetivo a atingir." (ROBALO, 1995, p.107)

Como observado, os conceitos são distintos, e, por isso, é necessário se tomar a devida atenção quando do estudo de um tema em que se busca responder a questão da eficácia e eficiência, até porque, com o descuido pode-se estar cometendo um erro ao se achar que se tratam de fato de sinônimos.

Então, de forma breve, eficiência se trata da forma como se obtém os resultados, enquanto a eficácia diz respeito diretamente ao objetivo, se é possível alcançá-lo, o que depende da estrutura do órgão, no caso, a SEMA/MT

\subsection{ESTRUTURA DA SEMA/MT REGIÃO DO BAIXO ARAGUAIA}

A Secretária de Estado de Meio Ambiente (SEMA), em sua Diretoria de Unidade Desconcentrada da cidade de Barra do Garças-MT (DUDBARRA), prevista na lei complementar do Estado de Mato Grosso $n^{\circ} 214 / 2005$, para a realização de suas atividades fiscalizadoras, conta com: 13 computadores, 04 máquinas fotográficas, 04 GPS (Global Positioning System), 03 impressoras sob o regime de locação, além de 02 veículos também 
sob locação e 01 próprio.

Já quanto a pessoal, a unidade de Barra do Garças conta com 18 servidores, nestes incluídos técnicos analistas e servidores externos.

No mesmo prédio onde se instala a DUDBARRA, funciona, também, a Gerência Regional do Parque Estadual Serra Azul (PESA), que conta com 02 computadores e 01 máquina fotográfica.

De acordo com a pesquisa realizada com o professor ex Diretor do Órgão, Cleber Fabiano Ferreira, durante os meses de dezembro de 2014 à fevereiro de 2015, a quantidade de computadores é suficiente para a realização dos procedimentos internos do órgão. Quanto ao número de máquinas fotográficas, o material de trabalho é classificado como insuficiente, bem como o número de GPSs. As impressoras suprem o necessário para os trabalhos internos.

Quanto ao número de veículos, este é insuficiente, tendo em vista que o campo de trabalho da SEMA é muito extenso, bem como o número de funcionários para o trabalho externo, pelo mesmo motivo dito no parágrafo anterior.

O Estado, segundo pesquisa de todo o material fornecido para trabalho na unidade de Barra do Garças, forneceu tão somente 30\% deste, sendo que o restante fora obtido por meio da chamada TAC (Termo de Ajuste de Conduta), uma espécie de transação feita com os indivíduos e empresas multadas em que, em compensação a multa, se entrega, diretamente ao órgão, materiais de trabalho.

\subsection{ATIVIDADES: SEMA/MT}

Um dos mecanismos utilizados pela SEMA no combate aos danos ao meio ambiente é o licenciamento ambiental, que, segundo o Manual de Licenciamento Ambiental da FIRJAN é:

É o procedimento no qual o poder público, representado por órgãos ambientais, autoriza e acompanha a implantação e a operação de atividades, que utilizam recursos naturais ou que sejam consideradas efetiva ou potencialmente poluidoras. É obrigação do empreendedor, prevista em lei, buscar o licenciamento ambiental junto ao órgão competente, desde as etapas iniciais de seu planejamento e instalação até a sua efetiva operação. (FIRJAN, 2004, disponível em: www.mma.gov.br)

Tal procedimento é obrigatório às atividades listadas no CONAMA 237 de 1997, que oferecem danos ao meio ambiente. Dentre tais atividades, pode-se listar, as industriais, mineradoras, madeireiras, químicas e infraestruturais, devem passar por dito procedimento a fim de que sua atividade seja fiscalizada e regulada para que não haja dano ao meio ambiente. 
Se tais atividades não passarem pelo devido processo de licenciamento, são impedidas de iniciar, tudo para que seja dado o devido tratamento ao meio ambiente.

O licenciamento ambiental se fundamenta na Lei 6.938/81, da Política Nacional do Meio Ambiente, que assim dispõe em seu inciso $\mathrm{V}$ do artigo $2^{\circ}$ :

Art. $2^{\circ}$ A Política Nacional do Meio Ambiente tem por objetivo a preservação, melhoria e recuperação da qualidade ambiental propícia à vida, visando assegurar, no País, condições ao desenvolvimento sócio-econômico, aos interesses da segurança nacional e à proteção da dignidade da vida humana, atendidos os seguintes princípios:

[...]

$\mathrm{V}$ - Controle e zoneamento das atividades potencial ou efetivamente poluidoras. (BRASIL, 1981, disponível em: www.planalto.gov.br)

Como se vislumbra, referido artigo da lei faz do licenciamento um princípio a ser adotado, sendo também um instrumento desta lei, conforme destaca o artigo $9^{\circ}$, inciso IV. sendo, in verbis: "são instrumentos da Política Nacional do Meio Ambiente: [...] o licenciamento e a revisão de atividades efetiva ou potencialmente poluidoras;" (BRASIL, 1981, disponível em: www.planalto.gov.br).

Nestes casos, o interessado é quem procura a Secretaria, devendo passar por 03 fases, a de licença prévia, na qual o órgão realizará um estudo para a instalação da atividade, verificando se existe possibilidade sob o ponto de vista ambiental de ser realizado o empreendimento; a licença de instalação, quando é autorizado o inicio da instalação da empresa realizadora da atividade nos moldes apresentados quando da obtenção da licença prévia, sendo que, em caso contrário a licença poderá ser cancelada; e, por fim, a licença de operação, que autoriza o inicio das atividades, o funcionamento da empresa, porém antes, é realizada nova fiscalização, com fins de verificar a observância dos requisitos descritos nas demais licenças já concedidas.

Pode-se dizer que este procedimento decorre do princípio da precaução, que é amplamente utilizado nas declarações produzidas em conferências ao redor do mundo.

E, o princípio da precaução observa não deve se utilizar de uma incerteza científica quanto a potencialidade do dano que determinada atividade poderá vir a causar para que se realize a atividade, devendo, antes de tudo, tomar as devidas precauções para que o dano não ocorra.

Na SEMA, região do baixo Araguaia, foram realizados um total de 213 processos de licenciamento ambiental entre os anos de 2011 e 2014, o que evidencia a ampla atuação do órgão.

Durante esses mesmo anos foram realizados o total de 240 notificações a 
atividades irregulares em questões ambientais. Esta é a primeira recomendação realizada pela SEMA, a qual é dada para que a empresa se regularize, para que não polua o meio ambiente.

A partir deste momento, não realizada a regularização na atividade, é registrada uma infração. Neste mesmo lapso temporal, foram realizadas 566 infrações, o que é a segunda recomendação efetuada pela SEMA.

Da mesma forma, não efetuada a normalização da atividade, será embargada a atividade, o que acontece em menor número. Utilizando o mesmo espaço de tempo, foram efetuados 20 embargos. E, tais embargos acontecem em menor número porque esta é a ultima instância, tendo em vista que bloqueia a atividade, cessando por inteiro a poluição causada, bem como o empreendimento.

Cumpre ressaltar que o núcleo da SEMA instalado em Barra do Garças-MT responde pela atuação em 16 cidades no Estado, sendo elas: Ribeirãozinho, Torixoréu, Pontal do Araguaia, Barra do Garças, General Carneiro, Novo São Joaquim, Campinápolis, Nova Xavantina, Água Boa, Nova Nazaré, Cocalinho Araguaiana, Canarana, Gaúcha do Norte, Ribeirão Cascalheira e Querência.

Para se ter uma ideia, a área de atuação da Unidade Desconcentrada de Barra do Garças, esta tem aproximadamente o tamanho do Estado do Rio de Janeiro, e chega a superar a área de alguns países da Europa, como Luxemburgo, por exemplo.

Como pode se observar, o campo de atuação do núcleo desconcentrado de Barra do Garças é muito grande, e isso dificulta e muito a eficácia do trabalho do órgão, que possui poucos recursos e pessoal para abranger todo esse espaço físico.

Além disso, o Estado de Mato Grosso não oferece com regularidade a liberação das diárias aos servidores para que realizem as diligências do órgão ficando por meses sem liberação de verba, paralisando todo o sistema e prejudicando o trabalho da Secretaria.

Sem as referidas diárias, a fiscalização do órgão acaba por ser falha, pois não pode se locomover até onde está sendo realizado o dano ambiental.

\section{CONSIDERAÇÕES FINAIS}

A Constituição Federal de 1988 em seu artigo 225 inova ao dar tratamento especial ao meio ambiente, elevando-o ao patamar máximo em nossa legislação e seguindo uma crescente internacional que exige do Estado a proteção integral do meio para que as presentes e futuras gerações tenham um ambiente sadio para viver com qualidade, assegurando-se, assim, o princípio da dignidade da pessoa humana, também previsto na 
Constituição Federal como preceito balizador.

E, este trabalho, trata de analisar o papel fiscalizador da SEMA/MT na região do baixo araguaia, observando suas atividades em número e emitindo um juízo de valor, indicando se há ou não eficácia e eficiência no trabalho empregado pelo órgão.

Cumpre ressaltar que, as propostas contidas no inicio da pesquisa foram atingidas, visto que, com os números disponibilizados pela Secretaria quanto as suas atividades e diligências, corroborados com os comentários do professor Cleber Fabiano Ferreira, sobre os mesmos, é possível se fazer uma análise, que, apesar de superficial, nos conduz a uma posição concreta quanto ao desenvolvimento do papel fiscalizador da SEMA nessa região.

É importante frisar que os métodos utilizados na elaboração desta obra, como a pesquisa bibliográfica, a pesquisa documental e a pesquisa de campo no ambiente da Diretaria de Unidade Desconcentrada de Barra do Garças cumpre a expectativa inicial na obtenção dos dados necessários a correta conclusão deste artigo.

Esta pesquisa ainda permite um conhecimento maior sobre o meio ambiente, trazendo detalhes históricos do nascimento do pensamento, não só mundial, mas, também, nacional, que surgiu em 1972 em Estocolmo, na Conferência das Nações Unidas sobre o meio ambiente humano. Isto, além da análise junto a SEMA dos materiais disponibilizados pelo Estado para a realização de suas atividades e os números relativos a estas como forma de comparação.

E, daquela análise dos dados observados na SEMA, é possível chegar a conclusão e resposta ao problema proposto inicialmente de que, a Secretaria, é eficiente, contendo números expressivos quanto a sua atuação e diligência, isto é, obtém resultados com o modus operandi,e também pode ser considerada eficaz, pela atuação do órgão em si, mas isso se considerarmos a média do Estado de Mato Grosso, pois, observando o texto da lei que a institui, bem como a nossa Lei Maior, a Constituição Federal/88, o Estado vem se mostrando muito falho, pois muitas vezes, retém o envio de verba para as diárias dos servidores, para que possam cumprir as atividades necessárias ao correto funcionamento do sistema, diminuindo o número de processos de licenciamento, por exemplo, e aumentando os de notificações, infrações e embargos, paralisando ou fazendo cumprir as leis ambientais das atividades causadoras de dano ao meio ambiente.

Outra falha passível de se deduzir durante a pesquisa é a de abrangência da Diretoria de Barra do Garças, pois está encarregada da fiscalização de 16 municípios, área superior a vários países da Europa, e o pessoal disponibilizado, bem como a verba disponibilizada pelo Estado vem a ser insuficiente. 
É sabido, inclusive, que, por vezes, o Estado deixa de injetar dinheiro ao órgão por meses, e, se os servidores quiserem se diligenciar em algum tipo de fiscalização, devem usar dinheiro próprio, e, nestes casos, caso ocorra algum sinistro, o Estado se recusa a cobrir.

Logo, pelos dados trazidos, uma forma de solucionar o problema encontrado na Secretaria seria a liberação de mais verba para diárias dos servidores do órgão, para que cumpram suas diligências, e, se viável, a alteração da lei complementar no 214/2005 no que tange ao número de unidades desconcentradas, pois conta com um número muito reduzido de diretorias para atender a uma demanda muito grande de espaço físico, o que aumentaria a eficiência e certamente atingiria o objetivo da Carta Magna eficazmente.

Além disso, o Estado deveria promover mais concursos públicos para a área ou, para sanar o problema mais rapidamente, contratar servidores, pois o número da unidade de Barra do Garças é muito reduzido para a demanda de trabalho.

Ao se ler o texto da Constituição de 1988, o que se pode concluir é que o legislador constituinte tinha por objetivo uma abrangência muito maior de órgãos como a SEMA, bem como uma disponibilidade maior de recursos destinados a conservação do meio ambiente, pois, este é tratado como direito fundamental do povo no texto da lei, mas na realidade da mesma forma de outros pontos regulados por nossa Constituição, como a educação e a cultura, vem sendo deixado de lado pelo Estado, colocando em xeque a preservação para as futuras gerações do bem comum de uso do povo e fundamental à vida.

\section{REFERÊNCIAS BIBLIOGRÁFICAS}

BETIOL, Luciana Stocco. Responsabilidade civil e proteção ao meio ambiente. São Paulo: Saraiva, 2010.

BRASIL. Lei Complementar $n^{0}$ 214, de 23 de junho de 2005. Cuiabá: Assembléia Legislativa do Estado de Mato Grosso, 2005. Disponível em:< http://app1.sefaz.mt.gov.br/sistema/legislacao/LeiComplEstadual.nsf/250a3b130089c1cc0425 72ed0051d0a1/635d6837e73434a90425702d0058fc80?OpenDocument>. Acesso em 18/01/2015.

Disponível

Constituição da República Federativa do Brasil. Brasília: Senado, 1988. em:<http://www.planalto.gov.br/ccivil_03/constituicao/constituicaocompilado.htm>. Acesso em $23 / 01 / 2015$.

Lei $\mathbf{n}^{0}$ 6.938, de 31 de agosto de 1981. Brasília: Congresso Nacional, 1981.

Disponível em: <http://www.planalto.gov.br/ccivil_03/leis/16938.htm>. Acesso em $18 / 01 / 2015$. 
Lei 9.605, de 12 de fevereiro de 1998. Brasília: Congresso Nacional, 1998. Disponível em:< http://www.planalto.gov.br/ccivil_03/leis/19605.htm>. Acesso em 23/01/2015

CHIMENTI, Ricardo Cunha et al. Curso de direito constitucional. 7. ed. rev. atual. até a EC n. 64/2010. São Paulo: Saraiva, 2010.

DINIZ, Maria Helena. Dicionário jurídico universitário. São Paulo: Saraiva, 2010.

CONFERÊNCIA DAS NAÇÕES UNIDAS SOBRE O MEIO AMBIENTE HUMANO. Declaração da conferência das naçoes unidas sobre o meio ambiente humano. $21^{\text {a }}$ Reunião plenária. Estocolmo, 16 de junho de 1972. Disponível em:<http://www.apambiente.pt/_zdata/Politicas/DesenvolvimentoSustentavel/1972_Declarac ao_Estocolmo.pdf $>$. Acesso em 20/03/2015.

FIRJAN. Manual de Licenciamento ambiental : guia de procedimento passo a passo. Rio de Janeiro: GMA, 2004. Disponível em:< http://www.mma.gov.br/estruturas/sqa_pnla/_arquivos/cart_sebrae.pdf $>$. Acesso em 27/01/2015.

HISTÓRICO da Secretaria de Estado de Meio Ambiente de Mato Grosso. 2010. Disponível em:<

http://www.sema.mt.gov.br/index.php?option=com_content\&view=article\&id=123\&Itemid= 221> Acesso em 04/11/2014.

LEITE, José Rubens Morato, MOREIRA, Danielle de Andrade, ACHKAR, Azor El. Sociedade de risco: danos ambientais extrapatrimoniais e jurisprudência brasileira. Anais do XV Congresso nacional de pesquisa e Pós-Graduação em Direito, 2006, p. 1-30. Disponível

em:<http://www.conpedi.org.br/manaus/arquivos/anais/manaus/direito_ambiental_jose_r_mo rato_leite_e_outros.pdf $>$. Acesso em 14/09/2014.

ROBALO, António. Eficácia e eficiência organizacionais. Lisboa: INDEG/ISCTE, 1995, p. 105-116. Disponível em:< https://repositorio.iscteiul.pt/bitstream/10071/1383/5/robalo_RPG_1995.pdf>. Acesso em 18/09/2014. 


\section{ANEXO 1}

A entrevista degravada que segue, foi realizada por volta das 18 horas do dia 19/03/2015 com o professor Cleber Fabiano Ferreira, ex diretor da Diretoria de Unidade Desconcentrada da SEMA em Barra do Garças-MT e professor da Faculdade Cathedral.

Tal entrevista foi gravada e nela é abordado como a atuação do órgão poderia ser maximizada; se o Estado de Mato Grosso vem dando suporte ao órgão da forma correta e, por último; se a unidade barragarcense consegue atingir números expressivos com os recursos disponibilizados pelo Estado.

A entrevista foi assim feita:

1 - Como e o que poderia ser feito para melhorar a atuação do órgão?

Para melhorar a atuação do órgão o interessante seria, que fosse feita uma capacitação e contratação de pessoal por que a unidade hoje conta tão somente com 8 funcionários para atuar em uma área de 16 municípios, ou seja, uma área quase do tamanho do Estado do Rio de Janeiro, onde apenas 8 pessoas trabalham. Dentre esses 8 funcionários 2 são motoristas e o restante são técnicos, então essa quantidade é insuficiente.

Quanto a logística, não se tem equipamento a altura, são 2 veículos, apenas 1 é traçado e apesar de existir material náutico não tem ninguém que pilote o barc.

O Estado peca muito por não fomentar o órgão e então fica impossível fazer um trabalho eficaz se você não tem condições humanas, condições técnicas e condições de logística para trabalhar. E principalmente no Estado de Mato Grosso que é tão focado nessa questão ambiental, onde se visa tanto o dano ambiental em razão da produção agrícola que é muito grande, e principalmente desmatamentos, queimadas, a pesca predatória, além dos empreendimentos que são poluidores que também precisam ser licenciados e que também não tem pessoal suficiente pra fazer esse licenciamento 
acabando que a secretaria não consegue fazer essas atividades e o órgão acaba ficando abarrotado com tantos processos, com lentidão, uma burocracia exacerbada, o que deixa a população mato grossense que necessita dos serviços do órgão fique totalmente descontente, revoltado com sua atuação em virtude desse despreparo e principalmente com a falta de estrutura que a SEMA tem e acaba que o órgão recebe duras críticas por que o Estado é omisso nessa situação de cuidar do bem ambiental. O Estado de mato grosso tem feito leis excelentes mas nós não temos estrutura pra fazer essas normas valerem, não temos estrutura para dar eficácia a essas normas.

2 - O que dizer sobre os recursos disponibilizados pelo Estado?

Seria necessário um concurso público para a contratação de pessoal capacitado, de pessoal técnico, a SEMA hoje precisa urgentemente de um concurso público para a contratação tanto de técnicos quanto de analistas, os técnicos seriam os motoristas condutores de embarcação, o pessoal de apoio, principalmente para a fiscalização e a contratação através de concurso público de pessoal capacitado, como engenheiros, geólogos, advogados, toda a gama de profissionais que se necessita para que se tenha uma condução ambiental correta, e, evidentemente, aparelhamento do órgão, precisa-se de veículos, adequados, helicópteros pra fazer esse monitoramento, equipamentos de ponta como gps, notebook, palmtops, equipamentos que sejam utilizados e que de mais agilidade no processo de fiscalização, acompanhamento e gestão ambiental do Estado, isso tudo além de um investimento pesado no órgão, o que a muito tempo não é feito.

Eu diria que esses recursos são muito poucos e por isso não se consegue fazer um trabalho a contento. Por exemplo, o que se destinou a SEMA no ultimo ano foram 76 milhões de reais, para que se gaste em um ano com 11 regionais mais a capital, com combustível, diárias, compra de equipamento permanente, compra de material de consumo, enfim, de toda a logística de um órgão fiscalizador e gestor deve ser feita com esse orçamento, isso fora as licitações que são pagas, então é um valor que não comporta, fica muito a desejar. Com o dinheiro que o Estado investe no órgão realmente não dá pra fazer um trabalho de ponta, eficaz, que torne a população contente com o trabalho.

3 - Tendo por base os recursos disponibilizados pelo Estado, a unidade de Barra do Garças consegue atingir números satisfatórios?

Os números apresentados de autos de infração, de todo o trabalho que é feito, é muito além da média, os servidores da regional de Barra do Garças fazem "das tripas 
coração" para conseguir atingir essas metas, e, no Estado, a regional de Barra do Garças é a que tem a maior produtividade, alcançando a própria capital, por que aqui existe um trabalho coeso entre os servidores, que trabalham com a cooperação de ONG's, o Ministério Público também tem ajudado, o judiciário, as policias, e isso propicia que o trabalho seja feito de uma forma diferenciada, mas não por que o Estado proporciona, mas sim por que a unidade busca apoio em outros órgãos e em outros municípios, para que o trabalho seja desenvolvido. 